\title{
Detection and Genetic Analysis of Porcine Bocavirus in Different Swine Herds in North Central China
}

\author{
Mengmeng Liu, ${ }^{1}$ Yi Li, ${ }^{1}$ Dong Sun, ${ }^{2}$ Yihe Xia, ${ }^{1}$ Jinhai Huang, ${ }^{1}$ and Lili Guo ${ }^{3}$ \\ ${ }^{1}$ School of Chemical Engineering and Technology, Tianjin University, No. 92, Weijin Road, Nankai District, Tianjin 300072, China \\ ${ }^{2}$ Department of Veterinary Diagnosis and Production Animal Medicine, College of Veterinary Medicine, Iowa State University, Ames, \\ IA 50011, USA \\ ${ }^{3}$ Tianjin Center of Animal Disease Preventive and Control, Tianjin 300012, China
}

Correspondence should be addressed to Jinhai Huang; jinhaih117@163.com

Received 9 December 2013; Accepted 12 January 2014; Published 18 February 2014

Academic Editors: S. Cao and Q. Shen

Copyright (C) 2014 Mengmeng Liu et al. This is an open access article distributed under the Creative Commons Attribution License, which permits unrestricted use, distribution, and reproduction in any medium, provided the original work is properly cited.

\begin{abstract}
Porcine Bocavirus (PBoV) has been reported to be associated with postweaning multisystemic wasting syndrome and pneumonia in pigs. In this study, a survey was conducted to evaluate the prevalence of $\mathrm{PBoV}$ in slaughter pigs, sick pigs, asymptomatic pigs and classical swine fever virus (CSFV) eradication plan herds in five provinces of China (Henan, Liaoning, Shandong, Hebei and Tianjin) by means of PCR targeting NS1 gene of PBoV. Among the total of 403 tissue samples, $11.41 \%$ were positive for PBoV. The positive rates of spleen $(20.75 \%)$ and inguinal lymph node $(27.18 \%)$ are higher than those of other organs. PCR products of twenty PBoV positive samples from slaughter pigs were sequenced for phylogenetic analysis. The result revealed that $\mathrm{PBoV}$ could be divided into 6 groups (PBoV-a PBoV-f). All PBoV sequenced in this study belong to PBoV-a-PBoV-d with 90.1\% to 99\% nucleotide identities. Our results exhibited significant genetic diversity of $\mathrm{PBoV}$ and suggested a complex prevalence of $\mathrm{PBoV}$ in Chinese swine herds. Whether this diversity of $\mathrm{PBoV}$ has a significance to pig production or even public health remains to be further studied.
\end{abstract}

\section{Introduction}

Parvoviruses, members of the family Parvoviridae, are able to cause a broad spectrum of diseases in animals [1]. The family Parvoviridae is divided into two subfamilies: Densovirinae and Parvovirinae. In the subfamily Parvovirinae, genus Bocavirus is uniquely different from other four genera, Amdovirus, Dependovirus, Erythrovirus, and Parvovirus, in the genome components (http://ictvonline.org/). Bocavirus contains a single-stranded, 4-6 kilobases (kb) long, autonomously replicating DNA genome with terminal palindromic sequences [2-5]. In total, 4 open reading frames (ORFs) have been identified: ORF1 at the $5^{\prime}$ end encodes nonstructural protein NS1; ORF2 which is in the middle of the genome encodes nonstructural protein NP1, a unique Bocavirus characteristic structure that is absent in most other members of Parvoviridae [5]; overlapping ORF3 and ORF4 encodes structural proteins VP1 and VP2, respectively [5].

Bocavirus was discovered in both humans and animals $[6,7]$. In 2009, a novel boca-like virus was discovered in Swedish postweaning multisystemic wasting syndrome (PMWS) suffering pigs using random amplification and large-scale sequencing techniques [8-10]. PBoV has been detected in PMWS-affected swine herds, suggesting that it might also play a role in the pathogenesis of PMWS $[8,11]$. The $\mathrm{PBoV}$ grouping is confusing in different reports $[6,12]$ when different regions of genome (genome, NS1, VP1, or NP1) were used in the phylogenetic analysis and thus make the differentiating of novel PBoVs difficult. Porcine Bocavirus (PBoV1) based on partial VP1/2 genes was first discovered in PMWS affected pigs in Sweden [10], and then the complete genome of $\mathrm{PBoV}$ types 1 and 2 was characterized and reported in 2010 [12, 13]. Two novel PBoV types, 3 and 4, were discovered in Hong Kong based on the phylogenetic analysis of selected VP1 gene fragments [14]. The complete genome of PBoV type 5 was discovered and identified in piglet stool samples from a farm where piglets are experiencing clinical diarrhea [15]. Based on nonstructural (NS) gene, according to International Committee of Taxonomy of Viruses, PBoV can be classified into more than 5 genotypes with less than $95 \%$ 
sequence identity (http://ictvonline.org/) among different genotypes $[6,15]$.

The prevalence of Bocavirus in human has been reported as ranging from $1.5 \%$ to $24.6 \%$ in different human populations around the world [7]. Moreover, increasing evidences are emerging to support the role of Bocavirus as an etiologic agent in human lower respiratory tract infection [12]. Due to the close relationship between human and pigs, the possibility that human might be infected by $\mathrm{PBoV}$ cannot be completely ruled out, and studies on PBoV could potentially benefit public health. In China, discovery of $\mathrm{PBoV}$ has been intensively reported. It is necessary to understand the $\mathrm{PBoV}$ epidemic status and gene group distribution based on the identical NS1 gene standard. In this study, a survey on the prevalence of $\mathrm{PBoV}$ in different parts of China was conducted by PCR detection on collected pig tissue samples with NS1 gene specific primers. Partial PBoV NS1 genes of 20 positive samples were sequenced and compared with reference sequences. Our observations could provide information for understanding the circulation and variety of $\mathrm{PBoV}$ in different herds or regions of China and also for evaluating the role of $\mathrm{PBoV}$ in public health issue.

\section{Materials and Methods}

2.1. Sample Collection. A total of 403 pig samples from individual animals with variant tissue origins including inguinal lymph node, submandibular lymph node, lung, kidney, liver, and spleen were collected from five provinces in China from 2006 to 2012. Among the 403 samples, 183 were from slaughter pigs (100 from 2 farms in Henan, 43 from a farm in Shandong, and 40 from a farm in Liaoning), 70 were from sick pigs with clinical signs, including diarrhea, mild cough,or low fever in Hebei, 150 tonsils were collected from 60-day-old replacement gilt (130 from classic swine fever virus eradication plan performing herds, which are CSFVfree and 20 samples from noneradication plan performing gilt herds) in Tianjin breeding pig farm. Detailed sample information was summarized in Table 1 . All collected samples were stored at $-80^{\circ} \mathrm{C}$ until test was performed.

2.2. DNA Extraction. Each porcine tissue sample $(100 \mathrm{mg})$ was frozen in liquid nitrogen, grounded with a homogenizer, and suspended in $500 \mu \mathrm{L}$ PBS $(0.01 \mathrm{~mol} / \mathrm{L}, \mathrm{pH} 7.2)$. Approximately $300 \mu \mathrm{L}$ homogenate was used for DNA extraction with conventional phenol-chloroform extraction method. Briefly, the homogenate was mixed with $300 \mu \mathrm{L}$ lysis buffer (containing $10 \mathrm{mM}$ Tris-Cl, $1 \mathrm{mM}$ EDTA, and $0.1 \%$ SDS) and $10 \mu \mathrm{L}$ proteinase $\mathrm{K}(10 \mathrm{mg} / \mathrm{mL})$ and digested for 2 hours at $60^{\circ} \mathrm{C}$. The sample was then centrifuged for $10 \mathrm{~min}$ at $12,000 \times \mathrm{g}$. The aqueous upper phase was transferred to a new tube with $600 \mu \mathrm{L}$ Tris phenol added, then mixed by inverting for $3 \mathrm{~min}$, and centrifuged for $10 \mathrm{~min}$ at $12,000 \times \mathrm{g}$. The supernatant was transferred to a new tube mixed with the equal volume of phenol: chloroform: isoamyl alcohol $(25: 24: 1)$ mixture and then centrifuged for $10 \mathrm{~min}$ at $12,000 \times \mathrm{g}$. The aqueous upper phase containing DNA was precipitated with 1/10 volume of sodium acetate ( $3 \mathrm{~mol} / \mathrm{L}, \mathrm{pH} 5.2)$ and 2 volumes of precooled ethanol at $-20^{\circ} \mathrm{C}$ for 2 hours. After centrifugation for $10 \mathrm{~min}$ at $12,000 \times \mathrm{g}$, the DNA was washed with $70 \%$ ethanol, then dried naturally, and dissolved with TE buffer (RNase included). The extracted DNA was stored in $-20^{\circ} \mathrm{C}$ for further use.

2.3. PBoV Detection. To enlarge the detection probability of different PBoV isolates, primers (PBoV-F: $5^{\prime}$-ACAGGCAGCCGATCACTCACTAT- ${ }^{\prime}$ and PBoV-R: $5^{\prime}$-CTCGTTCCTCCCATCAGACACTT- $3^{\prime}$ ) were designed based on the conservative regions of NS1 gene. Each DNA extract (20 ng/ $\mu \mathrm{L}$, approximately) was amplified with PCR mixture containing $0.5 \mu \mathrm{L}$ of $10 \mu \mathrm{M}$ PBoV-F, $0.5 \mu \mathrm{L}$ of $10 \mu \mathrm{M}$ PBoV-R, $5 \mu \mathrm{L}$ of $10 \times$ PCR buffer, $0.1 \mathrm{U}$ Taq DNA Polymerase, $1 \mu \mathrm{L}$ of $0.4 \mathrm{mM}$ each dNTPs, and $1.5 \mu \mathrm{L}$ of DNA. DNAase-RNAase free water was added to make a total volume of $20 \mu \mathrm{L}$. Amplification reaction consisted of initial denaturation at $94^{\circ} \mathrm{C}$ for $6 \mathrm{~min}, 35 \mathrm{cycles}$ of denaturation at $94^{\circ} \mathrm{C}$ for $20 \mathrm{sec}$, annealing at $52^{\circ} \mathrm{C}$ for $30 \mathrm{sec}$, extension at $68^{\circ} \mathrm{C}$ for $55 \mathrm{sec}$, and final extension after cycling at $72^{\circ} \mathrm{C}$ for $5 \mathrm{~min}$. The PCR products were separated by electrophoresis on $1 \%$ agarose gel, and a band at the $680 \mathrm{bp}$ position confirmed the presence of PBoV.

2.4. Sequencing and Phylogenetic Analysis. PCR products of twenty $\mathrm{PBoV}$ positive samples were purified using a commercial PCR purification kit (Omega Bio-Tek, Inc, USA) and sequenced at the Beijing Genomic Analysis Center (Beijing). The sequences were deposited in GenBank and then were screened for sequence similarities using BLASTn against the nr database in GenBank. In addition, fifteen PBoV sequences from UK (GenBank accession numberS JF512472, JF512473), USA (JF713714, JF713715), Hong Kong (JF429834, JF429835, and JF429836), and China (JN621325, JN831651, JN681175, HM053693, HM053694, HQ291308, HQ291309, and HQ223038), five human Bocavirus isolates (JX257046, NC 012729, NC 012564, JN632511, and JX887481), one Feline Bocavirus (NC 017823), one California sea lion Bocavirus 2 (JN420366), one Canine Bocavirus (JQ692588), and one Myotis Bocavirus 1 (JQ814850) were downloaded from GenBank and used for phylogenetic analyses. For amino acid analysis, sequences were manually adjusted for the correct reading frame.

Phylogenetic trees were generated using the neighbor joining (NJ) method with bootstrap of 1,000 replicates using MEGA 5.1 software (http://www.megasoftware.net). Percent bootstrap support was indicated at each node. GenBank accession number was indicated at each branch.

\section{Results}

3.1. Prevalence of PBoV among Different Pig Herds in China. Overall of the 403 samples tested, 46 (11.41\%) were found to be positive for PBoV by PCR (Table 1). The prevalence of PBoV in inguinal lymph node $(27.18 \%, 28 / 103)$ and spleen $(20.75 \%$, $11 / 53$ ) was significantly higher than that in submandibular lymph node $(6.25 \%, 5 / 80)$ and tonsil $(1.30 \%, 2 / 130)$. No PBoV 
TAble 1: Prevalence of PBoV detected by PCR in the pig samples in China.

\begin{tabular}{|c|c|c|c|}
\hline Origin & Type of tissue or samples & Number positive/number tested (\%) & Number sequenced \\
\hline \multirow{2}{*}{ Kaifeng (Henan) } & ILN & $9 / 20(45.00)$ & \multirow{4}{*}{5} \\
\hline & SLN & $0 / 20(0.00)$ & \\
\hline \multirow{2}{*}{ Luohe (Henan) } & ILN & $2 / 40(5.00)$ & \\
\hline & SLN & $0 / 20(0.00)$ & \\
\hline \multirow{2}{*}{ Shandong } & ILN & $15 / 23(65.21)$ & \multirow{2}{*}{14} \\
\hline & SLN & $3 / 20(15.00)$ & \\
\hline \multirow{2}{*}{ Liaoning } & ILN & $4 / 20(20.00)$ & \multirow{8}{*}{1} \\
\hline & SLN & $0 / 20(0.00)$ & \\
\hline \multirow{4}{*}{ Hebei } & Kidney & $0 / 3(0.00)$ & \\
\hline & Spleen & $11 / 53(20.75)$ & \\
\hline & Liver & $0 / 6(0.00)$ & \\
\hline & Lung & $0 / 8(0.00)$ & \\
\hline \multirow{2}{*}{ Tianjin } & Tonsil (group A) & $1 / 20(5.00)$ & \\
\hline & Tonsil (group B) & $1 / 130(0.77)$ & \\
\hline Total & & $46 / 403(11.41)$ & 20 \\
\hline
\end{tabular}

Note: inguinal lymph node (ILN; lnn. inguinales superficiales); submandibular lymph node (SLN; lnn. mandibulares); tonsil (group A), classical swine fever virus (CSFV) eradication plan herds; tonsil (group B), nonclassical swine fever virus (CSFV) eradication plan herds.

was tested in lung $(0 \%, 0 / 8)$, kidney $(0 \%, 0 / 3)$, and liver $(0 \%$, $0 / 6)$ tissues.

Prevalence differences were observed existing in slaughter swine samples among different regions of China. Samples collected from Shandong showed a higher $\mathrm{PBoV}$ prevalence $(41.86 \%, 18 / 43)$ than those of Henan $(11 \%, 11 / 100)$ and Liaoning $(10 \%, 4 / 40)$.

3.2. Phylogenetic Analysis of PBoV. PCR products of $20 \mathrm{PBoV}$ positive samples were selected and sequenced. The sequences were deposited in GenBank (accession numbers JX885585, JX944649-JX944667).

Phylogenetic analysis was performed based on a $680 \mathrm{bp}$ fragment of NS1 gene using the 20 samples in this study and 24 representative reference strains from different hosts and locations over the world (Figure 1). Comparative sequence analysis of NS1 genes from PBoV, human Bocavirus, and other animal Bocaviruses showed distinguishable gene cluster among all those Bocavirus isolates. All PBoV NS1 sequences had $71.4 \%$ to $99 \%$ nucleotide identity with human Bocavirus and other animal Bocaviruses.

Human Bocavirus and animal Bocavirus except for $\mathrm{PBoV}$ strains had less than $64 \%$ identity and formed several separate clades. Feline Bocavirus NC017823 NS1 gene had 74.6\%78.3\% identity with HQ223038 and HQ291308 strains (PBoVf group) which were named as $\mathrm{PBoV1}$ in previously report [6]. The phylogenetic effect between PBoV and feline Bocavirus should be further evaluated. One canine Bocavirus sequence JQ692598 and California sea lion sequence JN420368 had a $69 \%$ identity and were grouped to one clade (Figure 1). All 5 human Bocaviruses can be divided into different subclades and are grouped separately from porcine Bocavirus and other animal Bocaviruses. From $88.5 \%$ to $92 \%$ identity within different human Bocaviruses sequences and $78.5 \%$ identity with Myotis Bocavirus JQ814850 sequences. This preliminary study shows divergence among Bocavirus strains $[6,8,13,16]$.
In our study, $\mathrm{PBoV}$ was divided into 6 different clades, PBoV-a PBoV-f. Group PBoV-a to PBoV-f sequences had 93.64\%, 91.1\%, 94.15\%, 90.93\%, 96.66\%, and 78.3\% identities within their group, respectively. Based on differences of $\mathrm{PBoV}$ NS1 gene, five gene groups (PBoV1-5) were divided as previous report $[6,15]$. PBoV-a sequences have $91.7 \%$ to $99 \%$ identities with each other as well as about $95 \%$ identity with published PBoV3 sequences from Hong Kong (JX429834), USA (JF713715, JF713714) or UK (JF512472), and more, 92\%-96\% identity with PBoV4 sequences from Hong Kong (JF429835, 429836) [17]. PBoV-b had 2 Shandong isolate sequences (JX944658, JX944667) which gave match with PBoV3 JN681175. PBoV-c had two sequences (JX944660, JX944651) which gave match with PBoV5 (JN621325, JN831651). PBoV$\mathrm{d}$ included 3 sequences (JX944655, JX944662) that gave match with PBoV4 (JF512473). PBoV-e includes two classical PBoV2 (HQ291309, HM053694 strains) and one previously named PBoV1 sequence HM053693. PBoV-f included two PBoV1 strains, HQ291308 and HQ223038, from China. Group PBoVa-d sequences had $89.7 \%$ identity while having $81.2 \%$ identity with groups $\mathrm{PBoV}-\mathrm{e}$ and $\mathrm{PBoV}-\mathrm{f}$. PBoV-a sequences had $93.64 \%$ (from $91.7 \%$ to $99 \%$ ) identity within the group and $87.54 \%$ and $88.98 \%$ identities with PBoV-e and $\mathrm{PBoV}$-f group sequences, respectively.

In this study, all 20 slaughter pig PBoV NS1 sequences located in PBoVa-d groups mean that all isolated NS1 genes are more relevant to traditional $\mathrm{PBoV} 3-5$ group isolates, which did not give match with any PBoV1-2 group reference sequences as previously reports $[6,15]$. The result indicated that the diversity genotype $\mathrm{PBoV}$ strains existed in China $[11,15]$.

About $83.3 \%$ amino acid identity of partly NS1 protein sequence was obtained in 20 strains of this study and 15 published porcine Bocavirus sequences, including PBoV1PBoV5 subtypes from China and USA (Figure 2). A similar amino acid sequence alignment result showed that all $\mathrm{PBoV}$ 


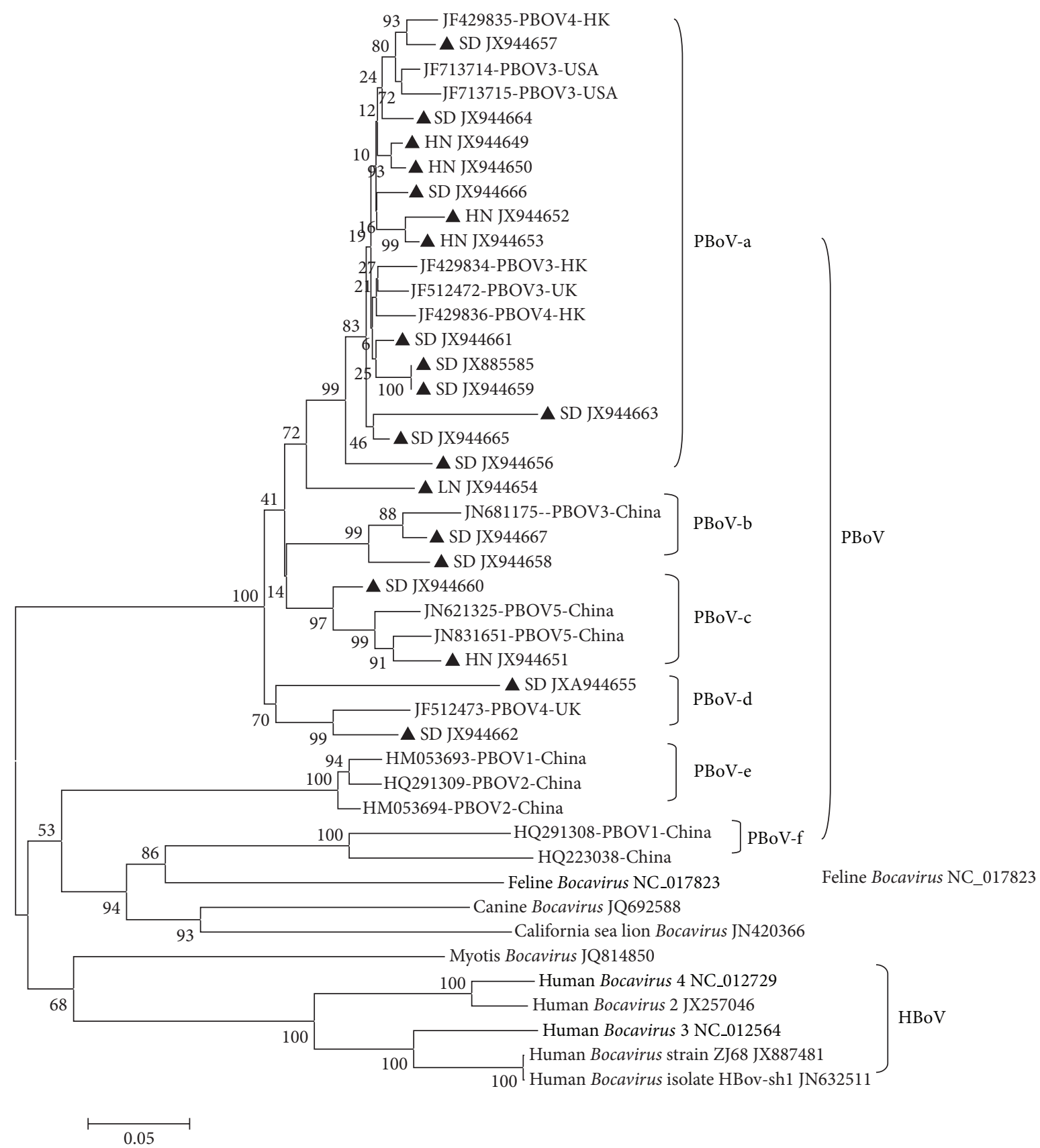

FIGURE 1: Phylogenetic tree constructed based on partial NS1 sequences of reference PBoV and PBoV from Chinese slaughter pigs. Slaughter pig sequences are labeled with $\boldsymbol{\Delta}$ and their corresponding accession numbers. The phylogenetic tree was constructed by MEGA ver. 5.1 with neighbor-joining method using 1,000 bootstrap replicates.

strains sequenced in this study are more related to $\mathrm{PBoV} 3$, PBoV4, and PBoV5 (90.38\% similarity) but distinct from PBoV1 and PBoV2. Basing the clustering on the NS1 gene or amino acid sequences, it was not possible to consistently cluster the strains into similar groups [6]. For example, strains PBoV1-HM053693, PBoV1-HQ291309, and PBoV2HM053694 in the gene NS1 based phylogenetic tree (Figure 1) were separated by additional PBoV1-HQ291309 in the amino acid NS1 phylogenetic tree (Figure 2). These differences may be due to crossover recombination during the speciation of these viruses as suggested $[6,14]$.

\section{Discussion}

Our survey tested collected tissue samples from multiple provinces of China. Positive tissue samples were detected from all provinces, implying that $\mathrm{PBoV}$ is widely distributed Chinese swine herds. Prevalence rates among provinces are 


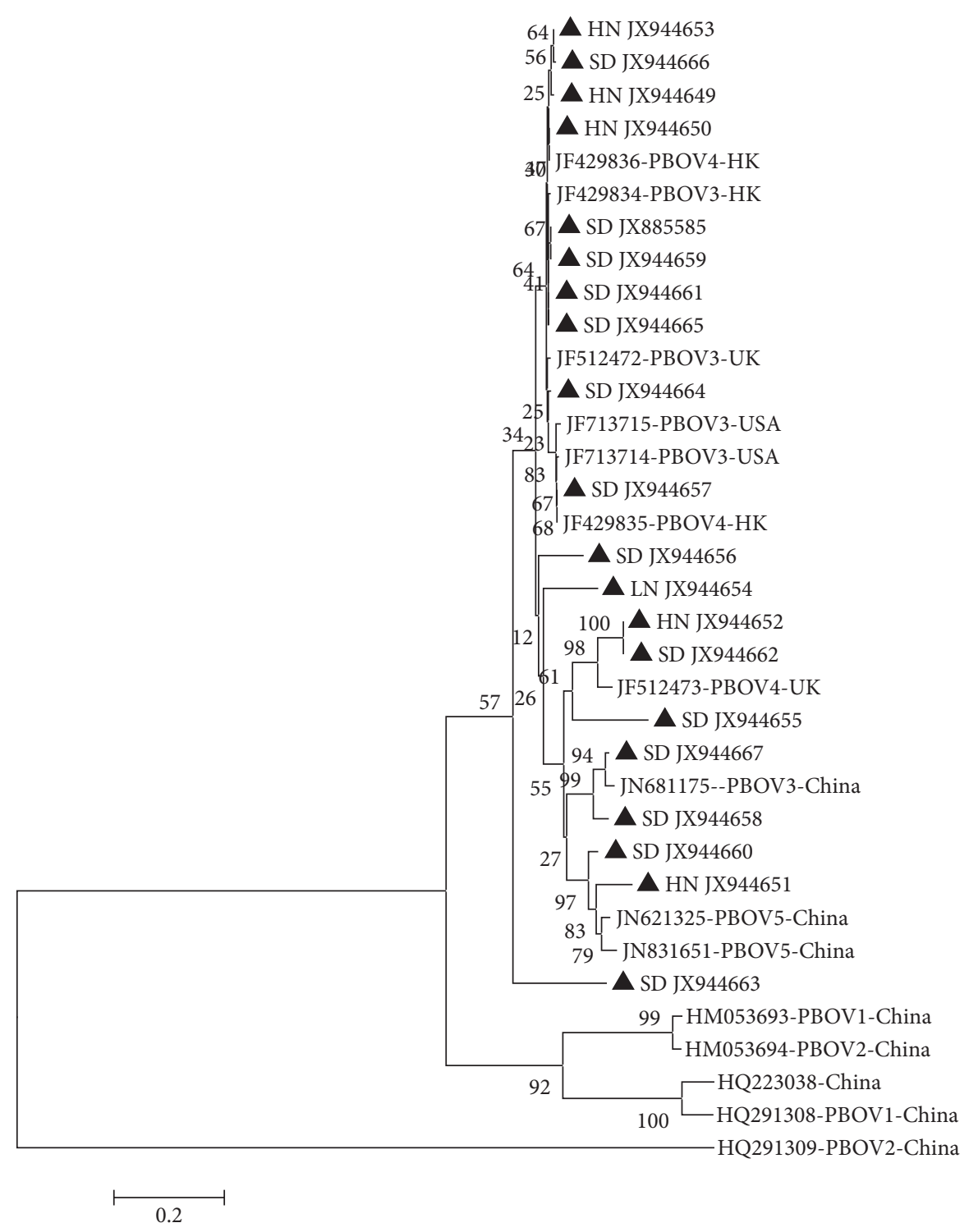

FIgURE 2: Phylogenetic tree constructed based on partial NS1 amino acid sequences of reference PBoV and PBoV from Chinese slaughter pigs. Slaughter pig sequences are labeled with $\mathbf{\Delta}$ and their corresponding accession numbers. The phylogenetic tree was constructed by MEGA ver. 5.1 with neighbor-joining method using 1,000 bootstrap replicates.

variant. A higher portion of $\mathrm{PBoV}$ presence was observed in the samples from Shandong province than those from other provinces. $\mathrm{PBoV}$ is distributed differently in tissues. $\mathrm{PBoV}$ positive rate detected in inguinal lymph nodes was significantly higher $(P<0.05)$ than other tissue samples (submandibular lymph node, liver, spleen, etc.). Since samples we collected from pigs at different geographical locations are of different tissue origins, the difference of $\mathrm{PBoV}$ prevalence in location may be biased by tissue tropism of the virus. Similarly, the difference of PBoV prevalence in tissue could also be biased by geographical location. Further studies are needed to provide more comprehensive insight to this.

In our study, $\mathrm{PBoV}$ was divided into 6 different clades, $\mathrm{PBoV}-\mathrm{a} \sim \mathrm{PBoV}-\mathrm{f}$. Sequence analysis showed that all $20 \mathrm{PBoV}$ sequences were grouped into $\mathrm{PBoV}-\mathrm{a}-\mathrm{d}$ groups and showed a big difference from PBoVe-f group. Our results indicated that the diversity genotype PBoV strains existed in China and the current porcine Bocaviruses exhibited significant genetic diversity among different hosts [14].

Currently, the pathogenesis of $\mathrm{PBoV}$ remains to be clarified. PBoV can be detected in tissues, serum, and fecal samples from not only clinically normal pigs but also clinically sick pigs suffering from various disease manifestations including porcine circovirus associated disease (PCVAD) and respiratory disease [10, 16-18]. It is well known that porcine parvovirus type 1 is a causative agent of reproductive failure in sows, while the pathogenicity of other types of Parvoviruses $[6,11,19]$ and members of other genus such as Bocavirus or Covirus remain to be determined. Numerous experimental investigations reported that coinfection of PCV2 with other 
viruses can contribute to the development of the PMWS in pigs $[17,20,21]$. It needs to be confirmed by experiments whether it is the case for PBoV. Yet, the higher prevalence of PBoV detected in PMWS suffering pigs (88\%) is compared to pigs without PMWS (46\%) [8], and the presence of $\mathrm{PBoV}$ in pigs suffering from diarrhea or in weaning pigs with respiratory symptoms suggests that this virus may play a role in the development of PMWS [15] or respiratory diseases [5]. However, the exact role of $\mathrm{PBoV}$, either alone or in combination with other enteric viruses, in causing diarrhea of pigs need to be explored by experiments. In our current study, a higher $\mathrm{PBoV}$ prevalence was detected in inguinal lymph node (8/20) than submandibular lymph node $(2 / 20)$ by comparing 20 lymph node samples from different individuals, suggesting a higher PBoV viral load in inguinal lymph node. In addition, spleen (20.75\%) and inguinal lymph node $(27.18 \%)$ have much higher positive rates compared to other organs, suggesting that they might be the organs where PBoV multiplication takes place. Moreover, different Bocavirus sequences can be obtained from different tissues within the same host and that may represent different virus species and viral multiplication [14]. Comparing samples collected from CSFV eradication program performing herds with nonperforming herds in Tianjin breeding farm, only 1 in 130 tonsil samples $(0.77 \%)$ collected from CSFV eradication program performing herd, were detected as positive, while 1 in 20 tonsil samples (5\%) collected from nonperforming herd was positive. The rate is significantly lower $(P<0.05)$ compared to that of eradication program nonperforming herds (5\%), which implies that CSFV eradication plan may be of help to decrease coinfection of PBoV. Even though data is less sufficient, we believe that CSFV eradication plan helped to decrease coinfection of $\mathrm{PBoV}$, because generally good farm management could help farms to control diseases better.

Parvoviruses have been shown to have mutation rates as high as that of RNA viruses [13, 22]. The phylogenetic analysis confirmed that the recombination event occurred between $\mathrm{HBoV} 1$ and $\mathrm{HBoV} 4$ and generated $\mathrm{HBoV} 2$. $\mathrm{HBoV}$ strains were previously considered to have high sequence diversity, very low protein identity, broad intergenotype recombination between $\mathrm{HBoV} 1$ and $\mathrm{HBoV} 4$, and intragenotype recombination between $\mathrm{HBoV} 2$ variants $[13,16]$. In addition, recombination analysis showed possible recombination events in VP1 region of PBoV4 strains, suggesting that different strains/variants within the same host could have arisen from recombination, and coinfection of different Bocavirus strains could have a high chance of recombination [14, 23]. Many emerging viruses are zoonotic, causing epidemics in humans after overcoming the interspecies barrier through mutation or other genetic events such as recombination. Human Bocavirus is associated with lower respiratory tract infection, pneumonia [7]. In addition, the latest report showed that human Bocaviruscould integrate in the host genome by persisting in some infected tissues in the form of cccDNA and then contribute to the development of some lung and colorectal tumors [24]. Although the $20 \mathrm{PBoV}$ strains sequenced in our study are grouped distinctly with $\mathrm{HBoV}, \mathrm{PBoV}$ strains grouped in $\mathrm{PBoV}$-f are much more close to feline Bocavirus. Moreover, due to the close relationship between human, canine, feline, and pigs, the possibility that human might be infected by $\mathrm{PBoV}$ cannot be completely ruled out.

PBoV genomes have been found in slaughter offal (blood, lymph nodes, feces, etc.). Irregular disposal of those waste could disseminate the virus in water and pork. Pork products occupy a large proportion of food consumption in China, and $\mathrm{PBoV}$ is a potential human pathogen $[7,18,25]$, and thereby $\mathrm{PBoV}$ infection in slaughter pigs raises a big concern for food quality and safety and maybe even human welfare and regional trade. Efforts are needed to clarify the potential risks of $\mathrm{PBoV}$ to public health. A close attention needs to be put into the monitoring of this agent to ensure a relieved food supply chain.

\section{Conflict of Interests}

The authors declared no potential conflict of interests with respect to the research, authorship, and/or publication of this paper.

\section{Acknowledgments}

This work was supported by the National Natural Science Foundation of China (no. 31272540) and the National High Technology Research and Development Program of China (863 Program, no. 2012AA101605).

\section{References}

[1] F. Wang, Y. Wei, C. Zhu et al., "Novel parvovirus sublineage in the family of Parvoviridae," Virus Genes, vol. 41, no. 2, pp. 305$308,2010$.

[2] T. Allander, M. T. Tammi, M. Eriksson, A. Bjerkner, A. Tiveljung-Lindell, and B. Andersson, "Cloning of a human parvovirus by molecular screening of respiratory tract samples," Proceedings of the National Academy of Sciences of the United States of America, vol. 102, no. 36, pp. 12891-12896, 2005.

[3] K. C. Chen, B. C. Shull, E. A. Moses, M. Lederman, E. R. Stout, and R. C. Bates, "Complete nucleotide sequence and genome organization of bovine parvovirus," Journal of Virology, vol. 60, no. 3, pp. 1085-1097, 1986.

[4] A. Kapoor, N. Mehta, F. Esper et al., "Identification and characterization of a new bocavirus species in gorillas," PLoS ONE, vol. 5, no. 7, Article ID el1948, 2010.

[5] J. Manteufel and U. Truyen, "Animal bocaviruses: a brief review," Intervirology, vol. 51, no. 5, pp. 328-334, 2008.

[6] C. T. Xiao, P. G. Halbur, and T. Opriessnig, "Molecular evolutionary genetic analysis of emerging parvoviruses identified in pigs," Infection, Genetics and Evolution, vol. 16, pp. 369-376, 2013.

[7] Y. Deng, X. Gu, X. Zhao et al., "High viral load of human bocavirus correlates with duration of wheezing in children with severe lower respiratory tract infection," PLOS ONE, vol. 7, no. 3, Article ID e34353, 2012.

[8] A.-L. Blomström, S. Belák, C. Fossum et al., "Detection of a novel porcine boca-like virus in the background of porcine circovirus type 2 induced postweaning multisystemic wasting syndrome," Virus Research, vol. 146, no. 1-2, pp. 125-129, 2009. 
[9] A.-L. Blomström, S. Belák, C. Fossum, L. Fuxler, P. Wallgren, and M. Berg, "Studies of porcine circovirus type 2, porcine boca-like virus and torque teno virus indicate the presence of multiple viral infections in postweaning multisystemic wasting syndrome pigs," Virus Research, vol. 152, no. 1-2, pp. 59-64, 2010.

[10] S. Zhai, C. Yue, Z. Wei et al., "High prevalence of a novel porcine bocavirus in weanling piglets with respiratory tract symptoms in China," Archives of Virology, vol. 155, no. 8, pp. 1313-1317, 2010.

[11] L. Huang, S.-L. Zhai, A. K. Cheung, H.-B. Zhang, J.-X. Long, and S.-S. Yuan, "Detection of a novel porcine parvovirus, PPV4, in Chinese swine herds," Virology Journal, vol. 7, article 333, 2010.

[12] W.-X. Cheng, J.-S. Li, C.-P. Huang et al., "Identification and nearly full-length genome characterization of novel porcine bocaviruses," PLoS ONE, vol. 5, no. 10, Article ID e13583, 2010.

[13] X. Fu, X. Wang, B. Ni et al., "Recombination analysis based on the complete genome of bocavirus," Virology Journal, vol. 8, article 182, 2011.

[14] S. K. Lau, P. C. Woo, C. C. Yip et al., "Co-existence of multiple strains of two novel porcine bocaviruses in the same pig, a previously undescribed phenomenon in members of the family Parvoviridae, and evidence for inter-and intra-host genetic diversity and recombination," Journal of General Virology, vol. 92, no. 9, pp. 2047-2059, 2011.

[15] B. Li, J. Ma, S. Xiao et al., "Complete genome sequence of a novel species of porcine bocavirus, PBoV5," Journal of Virology, vol. 86, no. 2, pp. 1286-1287, 2012.

[16] D. Kesebir, M. Vazquez, C. Weibel et al., "Human bocavirus infection in young children in the United States: molecular epidemiological profile and clinical characteristics of a newly emerging respiratory virus," The Journal of Infectious Diseases, vol. 194, no. 9, pp. 1276-1282, 2006.

[17] D. Cadar, A. Cságola, M. Lorincz et al., "Genetic detection and analysis of porcine bocavirus type 1 (PoBoV1) in European wild boar (Sus scrofa)," Virus Genes, vol. 43, no. 3, pp. 376-379, 2011.

[18] T. Shan, D. Lan, L. Li et al., "Genomic characterization and high prevalence of bocaviruses in swine," PLoS ONE, vol. 6, no. 4, Article ID e17292, 2011.

[19] S. K. Lau, P. C. Woo, H. Tse et al., "Identification of novel porcine and bovine parvoviruses closely related to human parvovirus 4," Journal of General Virology, vol. 89, no. 8, pp. 1840-1848, 2008.

[20] S. Kennedy, D. Moffett, F. McNeilly et al., "Reproduction of lesions of postweaning multisystemic wasting syndrome by infection of conventional pigs with porcine circovirus type 2 alone or in combination with porcine parvovirus," Journal of Comparative Pathology, vol. 122, no. 1, pp. 9-24, 2000.

[21] R. M. Pogranichniy, K.-J. Yoon, P. A. Harms, S. D. Sorden, and M. Daniels, "Case-control study on the association of porcine circovirus type 2 and other swine viral pathogens with postweaning multisystemic wasting syndrome," Journal of Veterinary Diagnostic Investigation, vol. 14, no. 6, pp. 449-456, 2002.

[22] S. Duffy, L. A. Shackelton, and E. C. Holmes, "Rates of evolutionary change in viruses: patterns and determinants," Nature Reviews Genetics, vol. 9, no. 4, pp. 267-276, 2008.

[23] A. Kapoor, P. Simmonds, E. Slikas et al., "Human bocaviruses are highly diverse, dispersed, recombination prone, and prevalent in enteric infections," The Journal of Infectious Diseases, vol. 201, no. 11, pp. 1633-1643, 2010.

[24] V. Schildgen, M. Malecki, R. L. Tillmann, M. Brockmann, and O. Schildgen, "The human bocavirus is associated with somelung and colorectal cancers and persists in solid tumors," PLoS ONE, vol. 8, no. 6, Article ID e68020, 2013.

[25] A. Kapoor, E. Slikas, P. Simmonds et al., "A newly identified bocavirus species in human stool," The Journal of Infectious Diseases, vol. 199, no. 2, pp. 196-200, 2009. 

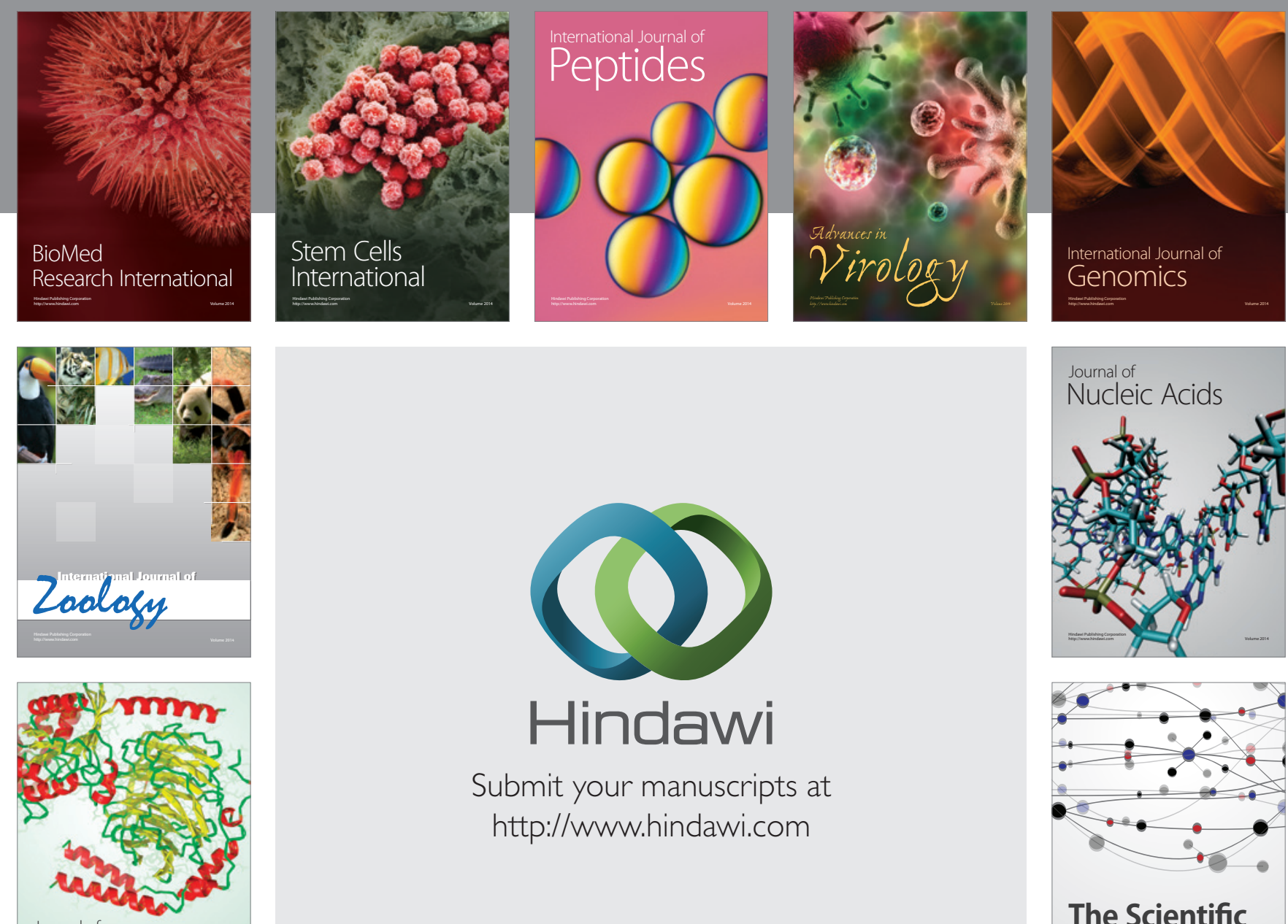

Submit your manuscripts at

http://www.hindawi.com

Journal of
Signal Transduction
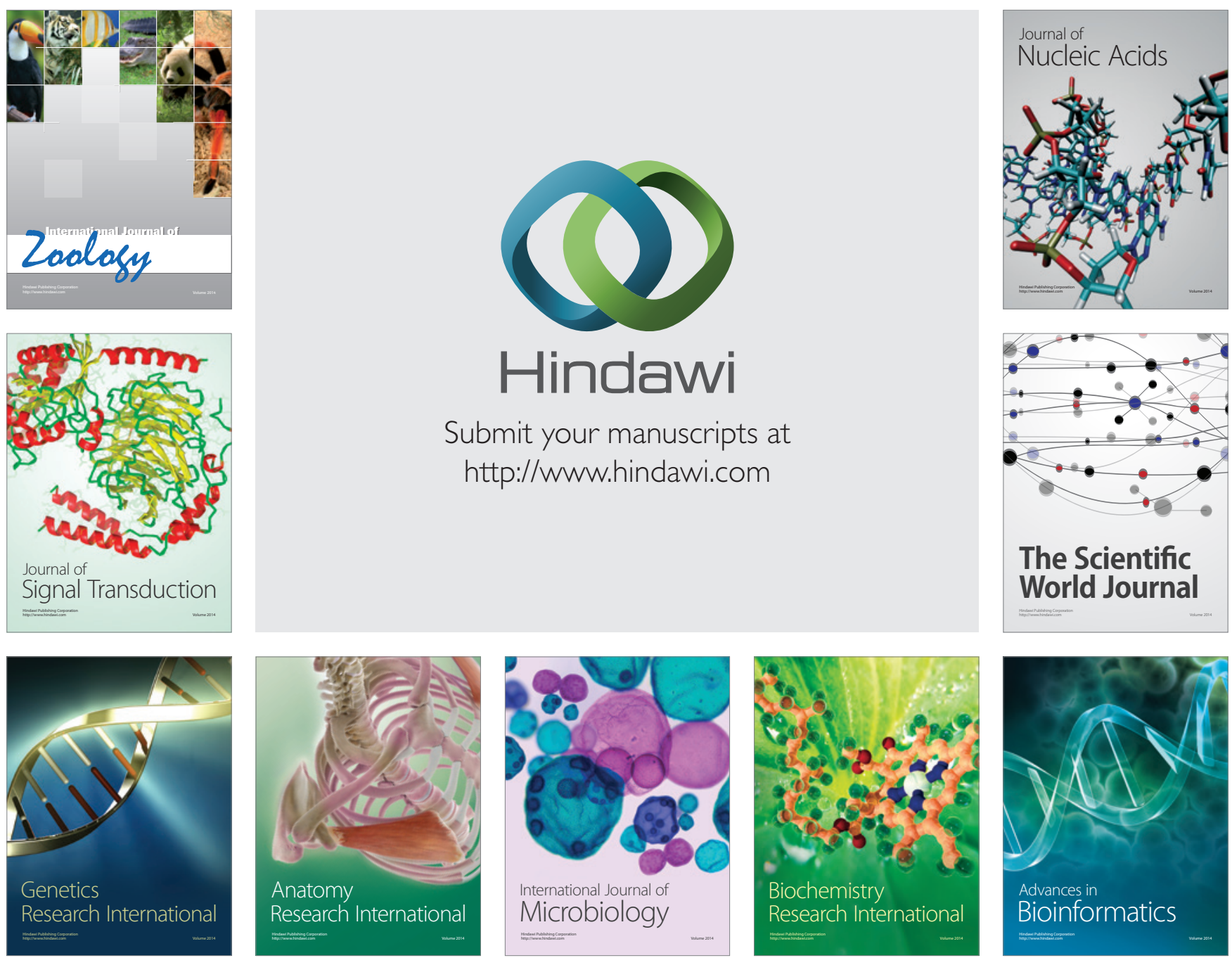

The Scientific World Journal
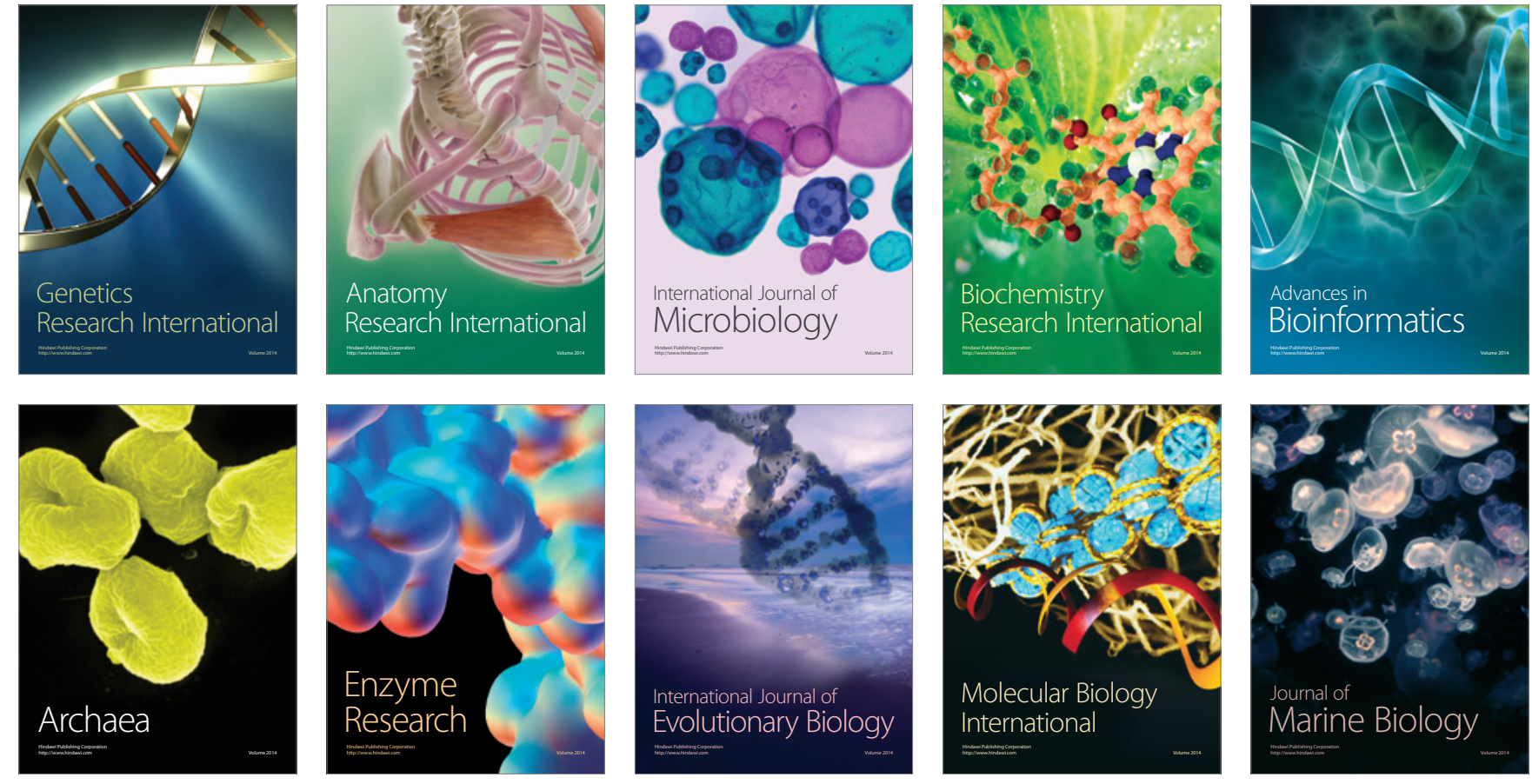